\title{
O aluno com Deficiência Intelectual e o ensino remoto durante a pandemia do novo Coronavírus: a realidade de uma escola do campo no interior do Paraná
}

Adriana Fátima de Campos*, Mônica Matos Barbosa**, Nayele Brandelero***

\section{Resumo}

O presente artigo tem como objetivo discutir o atual contexto, que devido à pandemia do novo coronavírus (COVID-19) afetou diversos setores da sociedade, incluindo a educação. Outrossim, visa-se analisar o ensino remoto no cenário público, destacando a experiência de uma escola do campo de uma cidade do interior do Paraná, para isso, expõe-se a prática com alunos com deficiência intelectual. O estudo de caso apresentou-se, metodologicamente, enquanto modo de pesquisa mais apropriado para tal produção. Percebeu-se que diante da nova realidade do ensino remoto, a educação do campo, já anteriormente desvalorizada, não consegue atender as demandas dos alunos, devido especialmente à falta de instrumentos tecnológicos para o acesso às aulas online.

Palavras-chave: Ensino remoto; Educação do campo; Inclusão.

\section{Introdução}

A educação brasileira, sobretudo a educação do campo, foi marcada ao longo de seu processo histórico, pelo descaso por parte de quem deveria garanti-la, o Estado. $\mathrm{O}$ desdém e a omissão deixaram marcas perceptíveis até a atualidade, trazidas à luz de maneira significativa pela pandemia.

* Programa de Pós Graduação em Educação PPGE - Universidade Estadual do Centro Oeste (UNICENTRO) Guarapuava - PR -Brasil. E-mail: adrii_fcampos@hotmail.com

* Programa de Pós Graduação em Educação PPGE - Universidade Estadual do Centro Oeste (UNICENTRO) Guarapuava - PR -Brasil. E-mail: monica_matos15@hotmail.com

.** Programa de Pós Graduação em Educação PPGE - Universidade Estadual do Centro Oeste (UNICENTRO) Guarapuava - PR -Brasil. E-mail: naya_brandelero@yahoo.com.br 
O contexto da pandemia do novo coronavírus (COVID 19) promoveu inúmeras ações de combate e prevenção da disseminação do vírus SARS-CoV-2, dentre elas, o isolamento social e a oferta de aulas remotas.

Esse formato de ensino propõe práticas pedagógicas mediadas por plataformas digitais, necessitando de tecnologia adequada, bem como acesso à internet e o mínimo de conhecimento prático de como acessá-los por parte dos alunos e professores. Tal sistema se mostra praticamente inviável na realidade de muitas escolas do Paraná, principalmente aquelas que são do campo, na qual a condição socioeconômica dos alunos não permite que os mesmos adquiram as ferramentas necessárias.

Assim, a presente produção, embasada na ótica qualitativa, se desenvolve sob forma de estudo de caso, realizada em uma escola do campo no interior do Paraná, aqui denominada como escola A. Participaram desse estudo um total de 28 alunos com deficiência intelectual e distúrbios de aprendizagem divididos em duas turmas de Sala de Recursos Multifuncionais (SRM), sendo que, apenas dois tinham acesso aos aplicativos digitais específicos para as aulas remotas, e o restante recebiam atividades impressas. O principal instrumento utilizado foi a observação. De acordo com Marconi \&Lakatos, 1999, se serve em especial dos sentidos com o intuito de obter aspectos da realidade em foco de análise. Desta forma, ver, ouvir e examinar fatos ou fenômenos constitui sua essência. Os autores apontam ainda que o planejamento sistemático, o registro metódico, bem como a verificação de segurança e validade são características que atribuem à observação o caráter científico.

A escolha de apresentar o Colégio do Campo A e sua realidade, justifica-se por estar inserida numa comunidade muito carente do município, além do número cada vez mais crescente de alunos com dificuldade de aprendizagem, o que quando investigados por meio de testes e avaliações, resultam em deficiências e distúrbios que sobrepassam a defasagem de conteúdo. Se justifica também, pelo acesso contínuo no colégio, pois uma das pesquisadoras trabalha e faz o atendimento na SRM, ou seja, presenciou essa realidade e acompanhou os diversos tipos de atendimento durante o ano de 2020.

O estudo está organizado em quatro seções e uma conclusão. Após a introdução, apresenta-se o conceito e discussão sobre educação do campo, inclusão e deficiência intelectual, em seguida discorre-se sobre a pandemia causada pelo novo coronavírus e o ensino remoto nas escolas do campo. Finaliza-se com o relato de experiência de educação remota para alunos com DI em uma escola do campo do interior do Paraná. 
Tal pesquisa evidenciou as dificuldades já enfrentadas na educação do campo e acentuadas com a pandemia causada pelo novo coronavírus, assim, ressalta-se a importância de tal pesquisa, visto que ela busca apresentar a realidade enfrentada pelos professores e alunos das escolas do campo, destacando as dificuldades de acesso às tecnologias necessárias, o que gera exclusão de tais alunos. Mediante tal cenário, é necessário discutir e criar ações que minimizem as desigualdades geradas pelo ensino remoto.

\section{Educação do Campo e a inclusão do aluno com Deficiência Intelectual}

A temática educação possui várias facetas e linhas de pensamento, citar-se-ão duas abordagens: Educação do Campo e Educação Inclusiva, com enfoque no atendimento ao aluno com deficiência intelectual.

Ao definir educação recorremos a Paulo Freire, que a concebe enquanto processo de interação e diálogo entre o educador e o educando, juntos criam a consciência de abrir-se do homem para o mundo. "Isso significa: 1) que ninguém educa ninguém; 2) que ninguém tampouco se educa sozinho, 3) que os homens se educam entre si, mediatizados pelo mundo. (FREIRE, 2011, p. 15).” O educando assume o papel de agente transformador dentro da sociedade.

Sobre essa visão, Saviani aborda que:

[...[ É pelo diálogo permanente e crítico, que professor e aluno fazem pesquisa, cujo objeto é a cotidianidade. Frutos da reflexão sobre a ação, as ideias então formadas não são aceitas como modelo, mas entendidas como parte de um processo de recriação permanente. E o trabalho educativo desenvolve-se baseado na realidade, na ação cotidiana do povo, de cada um, num processo constante de "ensinar a aprender o que seja pesquisar (SAVIANI, 2006, p. 51 e 52).

A educação tem por objetivo suscitar e desenvolver na criança estados físicos e morais que são requeridos pela sociedade. Portanto, a escola não está à margem da sociedade, ela é parte integrante e como tal, é um ambiente de socialização.

O espaço educacional é visto como um processo social, em que todos os indivíduos têm direito à educação. Em relação a isso, é importante discorrer sobre a inclusão. Incluir vai além de integrar, é um processo mais complexo, intenso e efetivo. Mais que um compromisso pedagógico e formal, a inclusão valoriza as diferenças e limitações, acreditando que não há saberes mais ou menos importantes, mas sim diferentes. Deve 
haver valorização da diversidade de saberes, de conhecimentos, de realidades, de pessoas. Para que essa inclusão seja efetiva, é necessária uma reorganização escolar, medidas que precisam ser tomadas como: adequação na infraestrutura, redução de número de alunos por turma, profissionais especializados, instrumentos tecnológicos, etc.

Inclusão escolar, sem exceção, abriga todas as pessoas, no âmbito de ensino, independentemente de cor, classe social e condições físicas e psicológicas. Assim, " $n a$ escola inclusiva professores e alunos aprendem uma lição que a vida dificilmente ensina: respeitar as diferenças, esse é o primeiro passo para construir uma sociedade mais justa" (MANTOAN, 2005, p. 24-26).

Diante do exposto, abordar-se-á a inclusão do aluno com deficiência intelectual em uma escola do campo. Para continuidade da discussão, faz-se necessário definir a deficiência intelectual, que de acordo com a definição de 1992 da Associação Americana de Desenvolvimento Mental (AAMR) refere-se ao funcionamento intelectual inferior à média, com limitações em pelo menos duas áreas de habilidades adaptativas, sendo elas: comunicação, cuidado pessoal, vida doméstica, habilidades sociais, utilização da comunidade, autogoverno, saúde e segurança, habilidades acadêmicas funcionais, lazer e trabalho (FIERRO, 2004). Ressalta-se que o DSM-5 (2014) aponta que o QI deve estar abaixo de 70 na escala Wechsler, com as limitações presentes antes dos 18 anos para definir tal disfunção.

A partir das explanações acima citadas, surge a questão da inclusão dosalunos com DI em escolas do campo. A Educação do Campo é uma área do ensino que atende as comunidades camponesas, resultado de uma luta constante dos movimentos sociais dos sujeitos que estão inseridos no espaço geográfico específico, ou seja, comunidades ribeirinhas, do meio rural, ilhéus, remanescentes quilombolas, comunidades indígenas, etc.

Recorre-se à definição de Educação do Campo, segundo o dicionário de Educação do Campo, como:

A Educação do Campo nomeia um fenômeno da realidade brasileira atual, protagonizado pelos trabalhadores do campo e suas organizações, que visa incidir sobre a política de educação desde os interesses sociais das comunidades camponesas. Objetivo e sujeitos a remetem às questões do trabalho, da cultura, do conhecimento e das lutas sociais dos camponeses e ao embate (de classe) entre projetos de campo e entre lógicas de agricultura que têm implicações no projeto de país e de sociedade e nas concepções de política pública, de educação e de formação humana. (CALDART et al, 2012, p. 259) 
Sabe-se que as populações do campo sempre foram esquecidas nas políticas públicas, o que também afetou o âmbito educacional. Apesar de passarem a ter mais notoriedade desde a década de 90 , as condições de ensino são precárias "colocam em evidência a histórica desigualdade educacional da sociedade brasileira, em que os trabalhadores são os que possuem menor escolaridade" (SOUZA, 2012, p.752).

A precarização de tais escolas certamente maximizam as desigualdades com o ensino remoto durante a pandemia, como será discutido a seguir.

\section{Pandemia do novo Coronavírus e o ensino remoto nas escolas do campo}

O ano de 2020 já iniciou com o surgimento de um vírus denominado novo coronavírus (SARS-CoV-2) causador da doença COVID-19 que se tornou uma das maiores epidemias da História. Devido à sua alta taxa e velocidade de contaminação, foram tomadas medidas para prevenir sua disseminação. Dentre elas, a Organização Mundial da Saúde orientou quanto ao isolamento e distanciamento social, o que afastou os alunos do espaço escolar (WHO, 2020).

De acordo com a Orientação do Estado do Paraná 009/2020-DEDUC/SEED, o Decreto Estadual n. ${ }^{\circ}$ 4.230, publicado em 16 de março de 2020, e alterado pelo Decreto Estadual n.. 4.258 , de 18 de março de 2020, coordena as medidas que visam o enfrentamento da emergência de saúde pública de relevância internacional. Tal normatização, concebida em regime especial, contempla toda educação estadual. Evidencia-se que o escopo de tal documento consiste em gerir as atividades nas instituições durante o período de suspensão das aulas presenciais. Surge, então, a proposta de ensino remoto como forma emergencial para sanar a questão das aulas e cumprimento do calendário anual.

Segundo Hodgeset al. (2020) o ensino remoto propõe a utilização de tecnologias online digitais para atendimento circunstancial onde antes existia educação presencial.

Arruda (2020) acrescenta que a educação remota pode ocorrer em tempo real, permitindo a participação dos alunos de forma simultânea, como também através de gravações das aulas para alunos que não têm condições de assistir naquele momento.

Diante de tal realidade, uma questão emergente refere-se ao acesso aos equipamentos e à internet por parte dos alunos. Parte-se da premissa de que as populações 
residentes na zona rural arcam com prejuízos no ensino remoto, visto a ausência de computadores e acesso a internet na casa da maioria das famílias (BRASIL, 2017).

Em uma pesquisa documental realizada por Souza (2020) encontram-se análises de declarações de professores que atuam em escolas rurais frente ao ensino remoto, nas quais se evidencia que a maioria dos alunos encontra dificuldade em acompanhar as aulas remotas por não ter acesso à tecnologia e internet necessária. Assim, a saída encontrada pelos professores é o envio de atividades impressas.

Contudo, apenas o envio de atividades impressas, sem o acompanhamento do aluno seguindo os princípios do ensino presencial, se distancia do ensino remoto, que de acordo com Oliveira et al (2020, p. 12) "prioriza a mediação pedagógica por meio de tecnologias e plataformas digitais para apoiar os processos de ensino e aprendizagem em resposta à suspensão de aulas e atividades presenciais."

Behar (2020), ao comentar sobre o ensino remoto, afirma que as aulas ocorrem em tempo síncrono, através de videoaulas, de forma que, com a presença de professor e alunos em uma sala de aula digital, há observância da interação, se aproximando ao máximo da educação presencial.

Torna-se importante destacar ainda, que os estudos de Souza (2020) apontaram um outro empecilho quanto às atividades impressas entregues aos alunos, no que tange à baixa escolaridade dos pais e/ou responsáveis por auxiliar o aluno. Em relação a isso, Pereira e Castro (2019) apontam que os índices de analfabetismo da população do campo são altos, com taxas muito superiores se comparadas às taxas da população urbana.

Diante do exposto, sabe-se que o ensino remoto foi proposto como forma de garantir e manter a conexão escolar, assim, as inúmeras soluções tecnológicas de certa forma possibilitam o funcionamento das escolas e a continuidade da aprendizagem mesmo que de forma virtual. No entanto, é urgente a necessidade de discussões a respeito do ensino remoto nas escolas do campo, que como já explanado, foram afetadas negativamente, gerando ainda mais desigualdade se comparadas às escolas urbanas.

No próximo tópico, será contemplado o relato de caso específico de um colégio inserido no campo, sob a ótica de profissionais da educação que atuam como professoras especialistas da educação especial. 


\section{Ensino remoto para os alunos com Deficiência Intelectual: relato de uma escola do campo}

Frente à temática já abordada sobre a importância da inclusão, tanto no segmento da educação especial e da educação do campo, nasce o seguinte questionamento: como contextualizar um modelo de educação à distância na qual o aluno não consegue ter nem ao menos o acesso às aulas?

Este é o desafio e a realidade do Colégio do Campo A. A instituição é uma das cinco destinadas aos alunos oriundos do campo, de seu município no Paraná. Iniciou sua trajetória no ano de 1997, ofertando o ensino fundamental final, da $5^{\circ}$ série e $6^{\circ}$ série, sendo implantadas as outras séries de forma gradativa. (PPP, 2019). A história do colégio não difere das instituições de ensino do Brasil, marcada pela luta dos agentes envolvidos para garantir uma educação de qualidade.

Os educandos são os principais agentes dentro de uma escola, olhar para a diversidade presente no meio social, possibilita o respeito e a valorização destes, que já sofrem a exclusão no seio de uma sociedade capitalista, na qual os sujeitos do campo não são importantes para o "desenvolvimento econômico". Vale ressaltar que estes sujeitos, não são parte integrante de uma minoria latifundiária presente na região centro-sul do Paraná. O perfil socioeconômico dos alunos é precário, a maioria depende de bolsas ofertadas pelo governo para sua sobrevivência e sua renda não passa de um salário mínimo. (PPP, 2019)

O Colégio tem como política interna que consiste em integrar os alunos entre si, para se tornar um todo em todas as esferas possíveis, em suma, um espaço de socialização. Um exemplo disso é a Sala de Recurso Multifuncional (SRM) uma modalidade de ensino especializado no atendimento aos alunos que apresentam deficiências intelectuais.

A SRM está sendo ofertada no Colégio do Campo A, desde 2016. No ano de 2020, o colégio contou com vinte e oito alunos matriculados, divididos em duas turmas, uma no período matutino e outra no vespertino, os alunos que estudam no período matutino, participam da sala de recursos no período vespertino, e vice-versa, sendo que todos apresentam deficiência intelectual ou distúrbios de aprendizagem, comprovadas por laudos. O professor que faz o atendimento a esses alunos é especialista na área de Educação Especial. 
O sistema educacional orienta para que os alunos sejam atendidos em duas horas-aula a cada dois dias da semana. A terceira hora-aula fica a cargo de horas-atividade do professor, para preparar atividades, corrigi-las, entre outros afazeres. Contudo, por tratar-se de uma escola do campo e adaptar-se à realidade do aluno, o Colégio do Campo A, faz diferente. Como os alunos dependem de transporte escolar, não têm a possibilidade de assistir a duas aulas e voltarem para a casa, restando enquanto alternativa a permanência o dia todo na escola.

A realidade atual de pandemia traz o questionamento sobre o abismo social em que a escola do campo está inserida. Devido à necessidade de isolamento social, as aulas presenciais foram suspensas. Para que ocorresse o cumprimento do calendário foi implantado o sistema de aulas remotas. No Estado do Paraná, por meio de aplicativos como Classroom, que consiste numa sala de aula virtual, os alunos podem interagir com os/as professores/as e realizar atividades. Para assistir às aulas e se apropriar dos conteúdos, utilizam outro aplicativo, o Aula Paraná. São aulas gravadas por professores, e disponibilizadas para o acesso na plataforma digital do Youtube, por Canais televisivos, e por meio do aplicativo baixado no celular.

Contudo, para que isso seja possível, o aluno carece de um aparelho celular ou computador. Como isso não é compatível com a maioria dos alunos do Estado, a outra alternativa adotada é a entrega de materiais impressos com atividades e conteúdos, conforme cronograma de cada escola, na maioria das escolas do campo são realizadas mensalmente. O Colégio do Campo A, no ano de 2020 contabilizava 206 alunos matriculados, e apenas 23 acessaram o Classroom. Esses dados são referentes ao Painel de Indicadores Aula Paraná (BI), disponibilizado pela Secretaria de Educação do Paraná. Segundo o levantamento realizado pela equipe pedagógica, aproximadamente $30 \%$ conseguiram acesso à internet, e $20 \%$ dos alunos possuem computador em casa, o restante utilizou celular.

Os dados não refletem com transparência que, além da falta de recursos materiais, há a dificuldade em acessar aplicativos, ou seja, a maioria dos alunos do Colégio do Campo A não possui conhecimento digital.

Dos vinte e oito alunos matriculados na SRM, apenas dois conseguiram acessar o aplicativo Classroom, o restante dos alunos recebia atividades impressas, e com o auxílio limitado de dados móveis, solicitava explicações por aplicativo de mensagens. Vale destacar, que a maioria dos pais/responsáveis que tiveram em 2020 e continuarão a ter em 2021 a responsabilidade de auxiliar seus/as filhos/as, possui 
escolaridade muito baixa. Em conversas, era recorrente falas como: "professora, meu filho pede ajuda, mas eu não sei, estudei só até o $2^{\circ}$ ano do primário"; "por favor, ajude porque esse conteúdo é muito difícil"; "a minha filha fica nervosa por não saber fazer a tarefa, e eu também, porque estudei menos que ela"; estas são algumas dentre as mais diversas falas que refletem a baixa instrução escolar dos genitores. Outra característica presente entre os alunos consiste no fato de que a maioria trabalha em grandes fazendas que rodeiam a região, além de alunos oriundos de comunidades quilombolas. São pessoas muito simples, que sobrevivem com sua força de trabalho em meio a uma comunidade marcada pela violência e pobreza.

Sem recursos, sem infraestrutura, em meio ao caos e ao medo de contaminação, a alternativa que resta é atender o aluno com deficiência e do campo, conforme as possibilidades se apresentam. Estas, se limitam a conversas por aplicativo de mensagens (WhatsApp) e atividades encaminhadas de forma flexibilizada, que atendam à sua deficiência. Por meio de um trabalho colaborativo com os professores regulares e professores especialistas, foram flexibilizadas atividades e atendidos os pais/responsáveis e alunos pelo aplicativo de mensagens, explicando conteúdos por meio de vídeos, fotos e áudios.

Outro recurso a que muitas escolas aderiram foi a busca ativa. Esta consiste na ida de professores e/ou equipe pedagógica até a casa do aluno, quando o mesmo não faz as atividades ou não conseguiu ter acesso a elas. Devido à falta de transporte escolar, muitas famílias estão reclusas em suas comunidades, muitas delas há quilômetros de distância da escola, sem recursos para se locomover, em muitos casos, dependem de vizinhos levarem/trazerem atividades para seus filhos. Há também famílias que moram isoladas, como foi o caso de uma busca ativa realizada no Colégio do Campo A: a aluna "1", diagnosticada com deficiência intelectual, mora numa comunidade muito distante da escola. Para que a aluna tivesse acesso às atividades foi necessário levá-las até ela, cumprindo as recomendações de higiene. A cada entrega se faziam explicações rápidas de como realizá-las. Infelizmente, não se trata de um caso isolado.

Vulnerabilidade social e econômica, dificuldades na aprendizagem, falta de acesso a instrumentos tecnológicos, moradia no campo, todos esses fatores atrelados à educação à distância resultam na precarização da aprendizagem para moradores do campo. A falta de investimento na educação e em qualidade de vida para os marginalizados, hoje colhe seus resultados. 


\section{Considerações finais}

Não é novidade que a Educação no Brasil é tecida por fragilidades e precariedades desde seus primórdios. Somadas estas características à vulnerabilidade socioeconômica e, por conseguinte, à falta de recursos, obtém-se um combo que atinge os mais pobres e produz segregação, precariza o desenvolvimento e cerceia sonhos, muitos destes que não tiveram sequer a oportunidade de emergir.

Os relatos apresentados neste estudo apontam um problema que não corresponde somente ao cenário da pandemia mundial. Ocorre que o isolamento social e a necessidade das aulas remotas serviram para exceler a desigualdade tácita que constitui a educação brasileira e, sem pandemia, seguia mascarada sob a bandeira da 'educação para todos'.

A educação do campo e a educação especial são, isoladamente, esquecidas e marginalizadas por modelos que privilegiam resultados e não conseguem sequer garantir atendimento adequado às necessidades de tais realidades. Acrescido o ensino remoto, novamente se evidencia a ausência de política educacional específica, que contemple tais especificidades e seja pensada para elas. As soluções encontradas, como aponta o relato de caso, são fruto do anseio dos educadores em atender seus alunos da melhor forma possível. No entanto, não equivalem à educação anunciada pelos autores aqui contemplados como Freire (2011), Saviani (2006), Vygotsky (2007), haja visto que os alunos que mais carecem permanecem sem mediação, sem recursos de estímulo adequado, desprovidos do acesso aos recursos tecnológicos e consequentemente excluídos da pertença ao modelo educacional proposto, ao contato com iguais e com professores.

Afere-se a relevância de levar em consideração a realidade social na qual os alunos estão inseridos. Não há como separar o que se conhece de quem o conhece, por isso, ambos os sujeitos (docente e discente) são fundamentais para que a aprendizagem aconteça. Deixá-los à mercê de soluções precárias como as narradas neste estudo, revela o descaso das políticas públicas educacionais tanto para a educação do campo quanto para a educação especial. 


\section{Students with Intellectual Disabilities and remote teaching during the new Coronavirus pandemic: the reality of a rural school in the countryside of Paraná}

\section{Abstract}

Thisarticleaimstodiscussthecurrentcontext, whichduetothepandemicofthe new coronavirus (COVID-19) affectedseveralsectorsofsociety, includingeducation. Furthermore, theaimistoanalyzeremoteeducation in thepublicscenario, highlightingtheexperienceof a rural school in a city in the interior of Paraná, for this, thepracticewithstudentswithintellectualdisabilitiesisexposed. The case studypresenteditself, methodologically, as themostappropriateresearchmethod for suchproduction. It wasnoticedthat in the face ofthe new reality ofremoteeducation, rural education, previouslydevalued, cannotmeetthedemandsofstudents, especiallyduetothelackoftechnologicalinstruments for accessto online classes.

Keywords: Remote teaching, Countrysideeducation, Inclusion.

\section{Referências}

ARRUDA, Eucídio Pimenta. Educação remota emergencial: elementos para políticas públicas na educação brasileira em tempos de Covid-19. Revista EmRede, v. 7, n. 1, p. 257-275, 2020.

BEHAR, Patrícia Alejandra. O ensino remoto emergencial e a educação à distância. Universidade Federal do Rio Grande do Sul/UFRGS, 2020. Disponível em: <https:/www.ufrgs.br/ jornal/o-ensino-remoto-emergencial-e-a-educacao-a-distancia/>. Acesso em: fev/ 2021.

BRASIL. Censo Agropecuário 2017. Brasília, 2017. Disponível em: <https://censos.ibge.gov.br/ agro/2017/>. Acesso em: fev. 2021.

CALDART, Roseli Salete. et al (org) Dicionário da Educação do Campo. Rio de Janeiro, São Paulo: Escola Politécnica de Saúde Joaquim Venâncio, Expressão Popular, 2012. Disponível em: <https://wp.ufpel.edu.br/consagro/files/2012/08/CALDART-Dicion\%C3\%A1rio-Campo-2012.pdf> Acesso em: Fev. 2020

CANDÓI, Colégio Estadual do Campo de Lagoa Seca. Projeto Político Pedagógico (PPP). Candói: 2019.

DSM-5 Manual diagnóstico e estatístico de transtornos mentais: DSM-5. 5. ed. Porto Alegre: Artmed, 2014.

FIERRO, Alfredo. Os alunos com deficiência mental. In:Coll, Marchesi, Palacios\& Cols. Desenvolvimento psicológico e educação. V. 3, 2004, p. 193-214.

FREIRE, Paulo. Educação como prática da liberdade. Rio de Janeiro: Paz e Terra, 2011.

HODGES, Charles. et al. The difference between emergency remote teachingand online learning. EducauseReview. 27 mar. 2020. 
MANTOAN, Maria Teresa Eglér.;MARQUES, Carlos Alberto. A integração de pessoas com deficiência: contribuições para uma reflexão sobre o tema. São Paulo: Ed. SENAC, 1997.

MARCONI. Maria de Andrade.; LAKATOS, Eva Maria. Técnicas de pesquisa. São Paulo: Atlas, 1999.

OLIVEIRA, Maria Socorro de Lima. et al. Diálogos com docentes sobre o ensino remoto e planejamento didático. Recife: Edufrpe, 2021.

PEREIRA, Caroline. Nascimento; CASTRO, César. Nunes. Educação: contraste entre o meio urbano e o meio rural no Brasil. Boletim Regional, Urbano e Ambiental, v.21, p.63-74, jul./ dez. 2019.

SAVIANI, Nereide. Saber Escolar, Currículo e Didática: problemas da unidade conteúdo/ método no processo pedagógico. 5. Ed. Campinas, SP: Autores Associados, 2006.

SECRETARIA DE ESTADO DA EDUCAÇÃO. Superintendência de Educação. Orientação n⿳o 009/2020 - DEDUC/SEED. Curitiba: SEED/PR., 2020. Disponível em <http://www.educacao.pr.gov. br/Pagina/Instrucoes> Acesso em: fev. 2021.

SOUZA, Maria Antônia. Educação do Campo, desigualdades sociais e educacionais. $E d u$ cação e Sociedade, Campinas, v.33, n.120, p. 745-763, jul./set., 2012.

SOUZA, Everton. Escolas do campo e o ensino remoto: vozes docentes nas mídias digitais. Revista Cocar. V. 14, N. 30, p. 1-18, Set./Dez. 2020

VIGOTSKY, Lev. Semionovitch.; COLE, Michael. A formação social da mente: o desenvolvimento dos processos psicológicos superiores. 7. ed. São Paulo: Martins Fontes, 2007.

WHO- World Health Organisation. Rolling updatesoncoronavirusdisease (Covid-19) 2020. Disponível em: <https://www.who.int/emergencies/diseases/novel-coronavirus-19/events-as-they-happen> Acesso em: fev. 2021. 